\title{
APLIKASI MODEL OHLSON PADA SUB SEKTOR LOGAM DAN SEJENISNYA DI INDONESIA
}

\author{
Sopyan Irawan \\ Universitas Pendidikan Indonesia \\ sopyan.irawan@student.upi.edu \\ Imas Purnamasari \\ Universitas Pendidikan Indonesia \\ imaspurnamasari@upi.edu \\ Heraeni Tanuatmodjo \\ Universitas Pendidikan Indonesia \\ heraenitanuatmodjo@upi.edu
}

\begin{abstract}
Objective - To analyze the predictions of bankruptcy of sub-sector of metal and allied companies listed on the Indonesia Stock Exchange in 2010-2015.

Design/methodology/approach - This type of research is descriptive method with a total sample of 12 metal and allied sub-sector companies listed on the Indonesian Stock Exchange. The analysis technique used is bankruptcy prediction Ohlson's model (1980). The design of this research is the method of time series design with a period of research for 6 years.

Findings - Based on the research results Ohlson models can be used to analyze the bankruptcy of the metal and allied sub-sector companies.

Originality/value - The difference in this study lies in the object of research, study time, measuring tools, literature used, the theory used and the results of research.
\end{abstract}

Keywords: Financial Performance, Financial Distress, Bankruptcy, Ohlson's Model.

Type Article: Research paper

\section{PENDAHULUAN}

Kebangkrutan merupakan hal yang tidak diinginkan oleh perusahaan dan pemangku kepentingan lainnya. Kebangkrutan merupakan permasalahan yang dapat terjadi pada perusahaan di berbagai negara. Kebangkrutan ditandai dengan penurunan laba dan ketidakmampuan melunasi hutang karena kurangnya likuiditas dan sering berpuncak pada pernyataan pailit (Altman, E.I. Hotchkiss, 2006:4). Isu kebangkrutan menjadi sangat penting dalam studi keuangan sejak kebangkrutan memberikan efek bagi ekonomi sebuah negara. (Pena, Martinez, \& Abudu, 2009:1).

Gitman \& Zutter (2012:741) menjelaskan kebangkrutan dalam arti hukum yaitu ketika perusahaan tidak dapat membayar tagihan atau saat kewajiban melebihi nilai pasar wajar dari aset, sebuah perusahaan dapat dinyatakan secara hukum bangkrut. Namun, kreditur umumnya mencoba untuk menghindarinya dengan memaksa suatu perusahaan yang memiliki kesulitan keuangan agar tidak bangkrut jika perusahaan tersebut memiliki kesempatan untuk berhasil dimasa depan. Dampak dari kebangkrutan hampir mengenai semua aspek dari bisnis yaitu arus kas, struktur keuangan, dan risiko. Hal terbaik bagi pemegang saham adalah untuk menghindari kesulitan keuangan dan kebangkrutan, tetapi jika hal itu terjadi penting untuk memahami bagaimana proses mempengaruhi nilai berkelanjutan dari perusahaan dan posisi dari berbagai investor perusahaan. (Brigham \& Daves, 2007:866).

Ketidakpastian ekonomi global sangat berdampak pada perlambatan pertumbuhan ekonomi di berbagai negara. Bank Dunia dalam Commodity Market Outlook January 2016 memproyeksikan harga logam secara keseluruhan dapat terkoreksi $10 \%$. Terkoreksinya harga logam terjadi akibat menurunnya permintaan pasar negara berkembang khususnya negara China dan peningkatan kapasitas produksi yang baru dilansir oleh market.bisnis.com (17/03/2016). Akibat dari menurunnya permintaan pasar maka akan terjadi penurunan keuntungan perusahaan yang ditandai dengan penurunan laba bersih atau net income. Penurunan laba juga terjadi di sub sektor logam dan sejenisnya. 
Prediksi terhadap kesehatan perusahaan perlu dilakukan agar terlihat kondisi perusahaanperusahaan yang termasuk kedalam sub sektor logam dan sejenisnya dapat tetap bertahan atau mengalami kebangkrutan, maka perlu dilakukan pengukuran atas kinerja perusahaan dengan mengukur kinerja keuangan perusahaan yang dapat dilakukan dengan menganalisis laporan keuangan yang dilaporkan perusahaan setiap periodenya. Analisa terhadap laporan keuangan dapat memberikan gambaran mengenai kondisi perusahaan di masa yang akan datang. Sebagaimana telah diuraikan oleh penelitian Avenhuis (2013:11) telah ada beberapa model analisis kebangkrutan, tetapi yang paling sering digunakan adalah model Altman, Ohlson, Zmijewski.

Penelitian Kleinert (2014:46) dalam tesisnya menjelaskan bahwa model Altman dan Ohlson memiliki tingkat akurasi yang tinggi dibandingkan dengan model Zmijewski karena model ini dinilai memiliki rasio keuangan yang tidak stabil dan kurang akurat dalam memprediksi perusahaan bangkrut dan tidak bangkrut. Kordlar \& Nikbakht (2011:335) dalam penelitiannya yang berjudul Comparing Bankruptcy Prediction Model in Iran menjelaskan bahwa model prediksi yang sering digunakan adalah model Altman dan Ohlson. Xu \& Zhang (2009:554) membandingkan performa model Altman dan Ohlson pada perusahaan yang berada di Jepang dan hasilnya performa model Ohlson lebih baik dibandingkan dengan model Altman. Adapun tujuan penelitian ini adalah untuk melihat gambaran analisis model Ohlson pada perusahaan logam dan sejenisnya yang terdaftar di BEI pada tahun 2010-2015.

\section{KAJIAN PUSTAKA}

Berdine (1995:462) mendefinisikan kinerja sebagai hasil dari kerja keras sebuah organisasi dalam mewujudkan tujuan stratejik yang telah ditetapkan oleh organisasi, kepuasan pelanggan serta kontribusinya bagi ekonomi masyarakat. Irham Fahmi (2014:142) berpendapat bahwa kinerja keuangan adalah analisis yang dilakukan untuk melihat sejauh mana perusahaan telah menerapkan aturan-aturan pelaksanaan keuangan yang telah memenuhi standar dan ketentuan dalam SAK (Standar Akuntasi Keuangan) atau GAPP (General Accepted Accounting Principle), dan ketentuan lainnya. Menurut Agnes Sawir (2005:1) kinerja keuangan adalah kondisi yang mencerminkan keadaan keuangan perusahaan berdasarkan sasaran standar dan kriteria yang telah ditetapkan oleh perusahaan tersebut. Berdasarkan pendapat di atas kinerja keuangan merupakan alat yang digunakan untuk mengukur kesehatan perusahaan, kinerja keuangan digunakan untuk mengukur efektifitas penggunaan aset oleh perusahaan dalam menjalankan bisnis dan memperleh pendapatan.

Kondisi keuangan perusahaan dapat diketahui melalui analisis laporan keuangan. Analisis laporan keuangan adalah menguraikan laporan keuangan perusahaan menjadi unit informasi dengan tujuan mengetahui kondisi keuangan lebih dalam yang sangat penting dalam proses pengambilan keputusan (Harahap, 2009). Menurut Gitman \& Zutter (2012:59) empat laporan keuangan utama yang dibutuhkan oleh perusahaan untuk dilaporkan kepada pemegang saham yaitu: (1) laporan laba rugi, (2) neraca, (3) laporan ekuitas, dan (4) laporan arus kas. Informasi yang terkandung dalam empat laporan keuangan dasar tersebut mencerminkan kinerja keuangan suatu perusahaan, menurutnya untuk menganalisa dan memantau kinerja keuangan melalui laporan keuangan dapat menggunakan rasio-rasio keuangan (financial ratos). Rasio keuangan dapat dibagi menjadi lima kategori dasar, yaitu: rasio likuiditas, rasio aktivitas, rasio hutang, rasio profitabilitas, dan rasio pasar (Gitman \& Zutter (2012:70).

Kebangkrutan adalah kegagalan bisnis yang terjadi ketika nilai yang dinyatakan dari kewajiban perusahaan melebihi nilai pasar wajar dari aset (Gitman, Zutter, Elali, \& Al-Roubaie, 2013:594), sedangkan menurut Brealey, Myers, dan Marcus (2001: 240) kebangkrutan adalah reorganisasi atau likuidasi dari perusahaan yang tidak dapat membayar utangnya. Menurut Undang-Undang Kepailitan No.4 Tahun 1998 pasal 1 butir (1), perusahaan dinyatakan pailit berdasar kepada putusan keadilan yang berwenang atau berdasarkan permohonan sendiri jika memiliki 2 atau lebih kreditur dan perusahaan tidak mampu membayar sedikitnya satu utangnya yang telah jatuh tempo. Bisa diartikan kebangkrutan adalah suatu kondisi dimana perusahaan tidak mampu lagi menjalankan kegiatan usahanya karena ketidakcukupan dana. Menurut Altman, E.I. Hotchkiss (2006:4) kebangkrutan didefinisikan dalam berbagai cara dalam upaya untuk menggambarkan masalah ekonomi yang terlibat. Empat definisi tersebut adalah failure, insolvency, default, dan bankruptcy.

$O$-Score merupakan model prediksi kebangkrutan yang diciptakan oleh James Ohlson pada tahun 1980, model prediksi Ohlson ini menggunakan analisis logit untuk mengembangkan model prediksi kebangkrutan dengan sembilan variabel independen (Kleinert, 2014:14). Rasio yang digunakan adalah rasio laverage, likuiditas, dan profitabilitas berdasarkan sempel 105 perusahaan bangkrut dan 2058 perusahaan tidak bangkrut. Model logit merupakan perkembangan lebih lanjut dari model 
probabilitas linier yang menjelaskan bahwa analisis model logit digunakan untuk estimasi probabilitas dari suatu fenomena dengan mereduksi kelemahan-kelemahan yang terdapat

\begin{tabular}{lcccccc}
\hline Emiten & $\mathbf{2 0 1 0}$ & $\mathbf{2 0 1 1}$ & $\mathbf{2 0 1 2}$ & $\mathbf{2 0 1 3}$ & $\mathbf{2 0 1 4}$ & $\mathbf{2 0 1 5}$ \\
& & & & & & \\
\hline ALKA & $-0,05$ & $-0,12$ & $-0,50$ & 8,82 & $-0,58$ & 0,72 \\
ALMI & $-0,90$ & 2,34 & $-0,30$ & 0,45 & 1,36 & $-2,32$ \\
& & & & & & \\
BTON & $-5,55$ & $-6,57$ & $-4,14$ & $-4,90$ & $-4,80$ & $-4,80$ \\
& & & & & & \\
CTBN & $-1,25$ & $-2,96$ & $-1,37$ & $-2,39$ & $-1,93$ & $-1,76$ \\
GDST & - & $-4,26$ & $-5,20$ & $-5,47$ & $-2,61$ & $-2,19$ \\
& 10,65 & & & & & \\
INAI & $-4,21$ & 0,07 & $-0,06$ & 0,55 & 0,07 & 0,37 \\
& & & & & & \\
JPRS & $-5,05$ & $-3,60$ & $-4,19$ & $-16,00$ & 5,12 & $-5,23$ \\
KRAS & $-2,00$ & $-1,06$ & $-0,40$ & 0,03 & 3,26 & 0,51 \\
LION & $-6,72$ & $-6,37$ & $-7,67$ & $-6,25$ & $-4,89$ & $-4,62$ \\
LMSH & $-3,49$ & $-3,00$ & $-5,50$ & $-4,87$ & $-5,16$ & $-5,17$ \\
NIKL & $-1,35$ & 0,88 & 0,30 & 1,10 & 0,77 & 1,05 \\
Rata- & & & & & & \\
rata & $-3,43$ & $-3,43$ & $-3,43$ & $-3,43$ & $-3,43$ & $-3,43$ \\
\hline
\end{tabular}

pada probabilitas linier. Berikut model prediksi kebangkrutan Ohlson (1980:118):

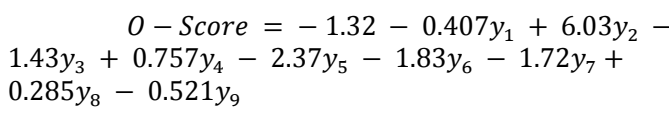

Titik pisah atau Cut-off pada model Ohlson yaitu nilai 0,50 , perusahaan diklasifikasikan bangkrut jika nilai $O$-Score diatas 0,50 . Sebaliknya jika nilai $O$-Score perusahaan dibawah 0,50 maka perusahaan diprediksi tidak mengalami kebangkrutan

\section{Gambar. 1 Kerangka Pemikiran}

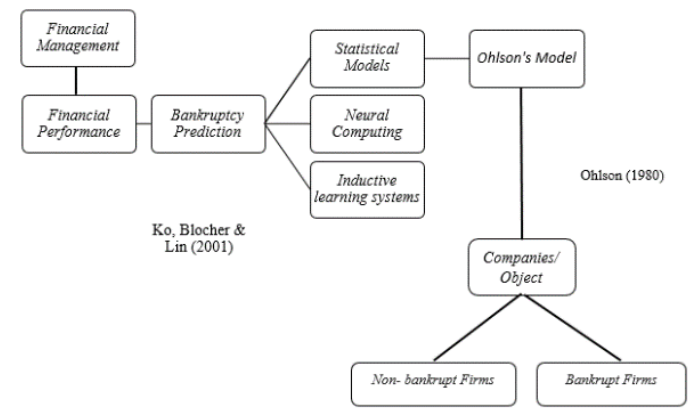

\section{METODE PENELITIAN}

Penelitian ini menggunakan pendekatan manajemen keuangan khususnya mengenai analisis prediksi kebangkrutan. Objek penelitian adalah sesuatu yang merupakan inti dari problematika penelitian (Suharsimi, 2009:29). Objek penelitian yang diteliti yaitu model prediksi kebangkrutan Ohlson. Berdasarkan objek penelitian tersebut, maka akan dilakukan analisis prediksi kebangkutan menggunakan model
Ohlson pada perusahana sub sektor logam dan sejenisnya tahun 2010-2015. Penelitian ini dilakukan pada 12 perusahaan sub sektor logam dan sejenisnya yang terdaftar di BEI, berdasarkan kurun waktu penelitian yang dilaksanakan pada kurun waktu enam tahun, maka desain penelitian yang digunakan adalah time series design.

Teknik pengumpulan data yang digunakan dalam penelilian ini adalah purposive sampling atau pengambilan data dengan tujuan tertentu, sedangkan teknik analisis data yang dilakukan adalah analisis deskriptif. Menurut Hermawan (2009:18) menyatakan bahwa penelitian deskriptif adalah penelitian yang memaparkan sesuatu karakteristik dari beberapa variabel dalam suatu situasi. Implementasi jenis penelitian deskriptif dalam penelitian ini adalah untuk menggambarkan kebangkrutan dengan model Ohlson pada perusahaan sub sektor logam dan sejenisnya tahun 2010-2015

\section{HASIL PENELITIAN DAN PEMBAHASAN Hasil Analisis Prediksi kebangkrutan}

James A. Ohlson mengembangkan model prediksi kebangkrutan yang dapat meramalkan probabilitas kebangkrutan sebuah perusahaan. Ohlson mengkombinasikan 9 rasio keuangan umum menjadi sebuah model prediksi kebangkrutan yang disebut o-score. Berikut merupakan hasil perhitungan model Ohlson:

\section{Tabel 1. Nilai O-Score}

Model Ohlson memiliki Sembilan rasio keuangan yaitu, Size, total liabilities devided by total asset, working capital devided by total assets, current liabilities devided by current assets, one if total liabilities exceeds total assets, zero otherwise, net income devided by total assets, funds provided by operation divided by total liabilities, one if net income was negative for the last two years, zero otherwise dan chin. Oscore kurang dari 0,50 dinyatakan dalam zona aman sedangkan o-score diatas 0,50 dinyatakan berpotensi mengalami kebangkrutan.

Hasil perhitungan pada Tabel 1 menunjukkan rata-rata $o$-score pada perusahaan sub sektor logam dan sejenisnya tahun 2010 sebesar -3,43, tahun 2011 naik 37\% menjadi 2,16 , tahun 2012 mengalami penurunan sebesar $13 \%$ menjadi -2,45, tahun 2013 mengalami penurunan 24\% sedangkan tahun 2014 mengalami kenaikan $64 \%$ dan tahun 2015 mengalami penurunan $o$-score $134 \%$. Rata-rata $o$ score perusahaan sub sektor logam dan sejenisnya mengalami fluktuasi yang cenderung memiliki tren positif, semakin kecil nilai o-score semakin baik kinerja perusahaan artinya kinerja perusahaan-perusahaan itu rata-rata mengalami 
kenaikan. Selanjutnya akan dijabarkan kinerja keuangan masing-masing perusahaan berdasarkan hasil analisis menggunakan model kebangkrutan Ohlson. O-score Alaska Industri (ALKA) pada tahun 2011 mengalami penurunan dari nilai $-0,05$ menjadi -0,12, selain itu Alaska Industri (ALKA) mengalami penurunan o-score pada tahun 2012 dan 2014, artinya kinerja keuangan perusahaan dalam keadaan sehat. Pada tahun 2013 nilai $o$ score sebesar 8,82 dan 2015 sebesar 0,73 menunjukkan bahwa kondisi perusahaan berada pada zona bangkrut.

O-score Alumindo Light Metal Industry (ALMI) pada tahun 2011 nilai mengalami kenaikan dari nilai $-0,90$ menjadi 2,34, selain itu Alumindo Light Metal Industry (ALMI) mengalami kenaikan o-score pada tahun 2013 dan 2014 masing-masing dengan nilai 0,45 dan 1,36, pada tahun 2011, 2013 dan 2014 o-score menunjukkan bahwa Alumindo Light Metal Industry (ALMI) dalam zona bangkrut. Tahun 2010, 2012 dan 2015 masing-masing nilai $o$-score yaitu $-0,90,-0,30$, dan $-2,32$ yang berarti perusahaan berada dalam kondisi yang sehat. $O$ score Beton Jaya Manunggal (BTON) pada tahun 2011 mengalami penurunan 18\%, tahun 2012 mengalami kenaikan 36\%. Tahun 2013 mengalami penurunan $18 \%$ dan mengalami kenaikan pada tahun 2014 dan 2015 masingmasing $2 \%$ dan $11 \%$. Nilai o-score pada periode 2010 sampai dengan 2015 menunjukkan Beton Jaya Manunggal (BTON) dalam zona sehat. $O$ score Citra Turbindo (CTBN) pada tahun $2011 \mathrm{o}$ score mengalami penurunan dari nilai $-1,25$ menjadi -2,96, tahun 2012 mengalami kenaikan $53 \%$, tahun 2013 nilai o-score mengalami penurunan menjadi -2,39, selanjutnya tahun 2014 dan 2015 mengalami kenaikan masing-masing sebesar $19 \%$ dan $8 \%$. selain itu score Citra Turbindo (CTBN) mengalami penurunan o-score pada tahun 2012 dan 2014. Pada periode 2010 hingga 2015 nilai o-score score Citra Turbindo (CTBN) menunjukkan bahwa kondisi perusahaan berada pada zona sehat.

O-score Gunawan Dianjaya Steel (GDST) pada tahun 2011 mengalami kenaikan dari nilai 10,25 menjadi -4,26, tahun 2012 dan 2013 mengalami penurunan masing-masing sebesar 22\% dan 5\%, sedangkan tahun 2014 dan 2015 nilai o-score mengalami kenaikan masing-masing menjadi -2,61 dan -2,19. Pada periode 2010 hingga 2015 nilai o-score Gunawan Dianjaya Steel (GDST) menunjukkan bahwa kondisi perusahaan berada pada zona sehat. O-score Indal Alumunium Industry (INAI) pada tahun 2011mengalami kenaikan dari nilai -4,21 menjadi 0,07, tahun 2012 mengalami penurunan menjadi 0,06, tahun 2013 mengalami kenaikan menjadi 0,55, selanjutnya tahun 2014 mengalami penurunan kembali menjadi 0,07 dan tahun 2015 mengalami kenaikan menjadi 0,36. Selama periode penelitian hanya nilai o-score Indal Alumunium Industry (INAI) tahun 2013 yang menunjukkan kondisi perusahaan berada pada zona bangkrut, artinya ditahun 2010, 2011, 2012, 2014 dan 2015 perusahaan berada di zona aman. $O$-score Jaya Pari Steel (JPRS) pada tahun 2011 mengalami kenaikan dari nilai $-5,05$ menjadi 3,60 tahun 2012 mengalami penurunan menjadi 4,19, tahun 2013 mengalami penurunan pesat menjadi -16, selanjutnya tahun 2014 mengalami kenaikan pesat menjadi 5,12 dan tahun 2015 mengalami penurunan menjadi $-5,23$. Selama periode penelitian hanya nilai $o$-score Jaya Pari Steel (JPRS) tahun 2014 yang menunjukkan kondisi perusahaan berada pada zona bangkrut, artinya ditahun 2010, 2011, 2012, 2013 dan 2015 perusahaan berada di zona aman.

O-score Krakatau Steel (KRAS) pada tahun 2011 mengalami kenaikan dari nilai $-2,00$ menjadi -1,06, tahun 2012 mengalami kenaikan menjadi 0,40 , di tahun selanjutya yaitu tahun 2013 mengalami kenaikan kembali menjadi 0,03, tahun 2014 mengalami kenaikan pesat dari 0,03 menjad 3,26 dan tahun 2015 menurun dari 3,26 menjadi 0,51 . Selama periode penelitian nilai $o$ score KRAS dari tahun 2010 hingga 2014 terus mengalami kenaikan, ini berarti kinerja perusahaan mengalami penurunan, tahun 2014 dan 2015 Krakatau Steel (KRAS) berada pada zona bangkrut. $O$-score Lion Metal works (LION) tahun 2011 o-score mengalami kenaikan sebesar 5,2\%, tahun 2012 mengalami penurunan sebesar 20\%, tahun 2013 mengalami kenaikan kembali sebesar 18,5\%, tahun 2014 naik 21\%, dan tahun 2015 naik sebesar 5\%, selama periode penelitian nilai $o$-score Lion Metal works (LION) dari tahun 2010 hingga 2015 berada dalam zona sehat. O-score Lionmesh Prima (LMSH) pada tahun 2011 mengalami kenaikan sebesar 14\%, tahun 2012 mengalami penurunan sebesar 83\%, tahun 2013 mengalami kenaikan sebesar 11\%, tahun 2014 mengalami penurunan 5,9\%, dan tahun 2015 turun sebesar 19\%, selama periode penelitian nilai o-score Lionmesh Prima (LMSH) dari tahun 2010 hingga 2015 berada dalam zona sehat.

O-score Pelat Timah Nusantara (NIKL) tahun 2011 mengalami kenaikan dari $-1,35$ menjadi 0,88 , tahun 2012 mengalami penurunan dari 0,88 menjadi 0,30 , tahun 2013 naik menjadi 1,10, tahun 2014 turun menjadi 0,77 dan tahun 2015 kembali naik menjadi 1,05. Selama periode penelitian nilai o-score Pelat Timah Nusantara (NIKL) tahun 2010 dan tahun 2012 berada di zona aman, sedangkan tahun 2011, 2013, 2014 dan 2015 berada dalam zona bangkrut. O-score Pelangi Indah Canindo (PICO) pada tahun 2011 
mengalami penurunan dari 0,01 menjadi $-0,39$, tahun 2012 mengalami penurunan kembal dari 0,39 menjadi $-0,43$, tahun 2013 turun menjadi 0,87 , tahun 2014 turun menjadi $-1,32$ dan tahun

\begin{tabular}{|c|c|c|c|c|c|c|c|}
\hline & \multirow[t]{2}{*}{ Emiten } & \multicolumn{6}{|c|}{ Tahun } \\
\hline & & 2010 & 2011 & 2012 & 2013 & 2014 & 2015 \\
\hline ALKA & $\begin{array}{l}\text { Alaska } \\
\text { Industrindo }\end{array}$ & TB & TB & TB & B & TB & $\mathrm{B}$ \\
\hline ALMI & $\begin{array}{l}\text { Alumindo } \\
\text { Light Metal }\end{array}$ & TB & B & TB & B & B & TB \\
\hline BTON & $\begin{array}{l}\text { Beton Jaya } \\
\text { Manunggal }\end{array}$ & TB & TB & TB & TB & $\mathrm{TB}$ & TB \\
\hline CTBN & Citra & TB & $\mathrm{TB}$ & TB & TB & $\mathrm{TB}$ & TB \\
\hline GDST & $\begin{array}{l}\text { Gunawan } \\
\text { Dianjaya }\end{array}$ & ТВ & $\mathrm{TB}$ & ТВ & TB & TB & ТВ \\
\hline INAI & $\begin{array}{l}\text { Indal } \\
\text { Alumunium }\end{array}$ & ТВ & TB & TB & B & TB & $\mathrm{TB}$ \\
\hline JPRS & $\begin{array}{l}\text { Inductury } \\
\text { Jaya Pari }\end{array}$ & TB & TB & TB & TB & B & TB \\
\hline KRAS & Krakatau & TB & TB & TB & TB & B & B \\
\hline LION & Lion Metal & TB & TB & TB & TB & TB & TB \\
\hline LMSH & Lionmesh & TB & TB & TB & TB & TB & TВ \\
\hline NIKL & $\begin{array}{l}\text { Pelat Timah } \\
\text { Nusantara }\end{array}$ & TB & B & TB & B & B & B \\
\hline PICO & $\begin{array}{l}\text { Pelangi } \\
\text { Indah }\end{array}$ & TB & TB & TB & TB & TB & TB \\
\hline
\end{tabular}

2015 turun menjadi -1,68, selama periode 2010 sampai dengan 2015 nilai o-score Pelangi Indah Canindo (PICO) menunjukkan bahwa perusahaan dalam zona aman.

Hasil penelitian secara deskriptif menunjukkan Alaska Industrindo (ALKA) selama periode 2010 hingga 2015 mengalami potensi kebangkrutan pada tahun 2013 saja dikarenakan $\mathrm{Y}_{5}$ yang menghitung rasio profitabilitas bernilai negatif, artinya perusahaan memiliki profitabilitas rendah dan $\mathrm{Y}_{6}$ yang mengukur rasio solvabilitas bernilai negatif artinya dana yang digunakan untuk kegiatan utama perusahaan banyak dibiayai dengan utang hal ini sesuai dengan konsep yang dijelaskan oleh Kordlar \& Nikbakht (2011:340) bahwa ciri perusahaan yang akan bangkrut yaitu memiliki total kewajiban relatif tinggi terhadap total asset atau penurunan yang lebih besar terhadap laba bersih. Perusahaan Alumindo Light Metal Industry (ALMI) mengalami potensi kebangkrutan pada tahun 2011, 2013 dan 2014. Tahun $2011 \mathrm{Y}_{9}$ bernilai negatif yang berarti ALMI mengalami penurunan laba bersih, sedangkan tahun 2013 dan $2014 \quad Y_{6}$ ALMI bernilai negatif yang mengakibatkan nilai OScore besar. Beton Jaya Manunggal (BTON) selama periode 2010 hingga 2015 tidak mengalami potensi kebangkrutan.

Perusahaan Citra Turbindo (CTBN) pada periode 2010 hingga 2015 tidak mengalami potensi kebangkrutan, Gunawan Dianjaya Steel (GDST) tidak memiliki potensi kebangkrutan selama periode penelitian. Indal Alumunum Industry (INAI) berpotensi bangkrut pada tahun 2013 dikarenakan $\mathrm{Y}_{9}$ bernilai negatif yang berarti INAI mengalami penurunan laba bersih yang signifikan, perusahaan Jaya Pari Steel (JPRS) memiliki potensi kebangkrutan hanya pada tahun 2014 dikarenakan $\mathrm{Y}_{5}$ yang menghitung rasio profitabilitas bernilai negatif, artinya perusahaan memiliki profitabilitas rendah, $\mathrm{Y}_{6}$ yang mengukur rasio solvabilitas bernilai negatif artinya dana yang digunakan untuk kegiatan utama perusahaan banyak dibiayai dengan utang dan $\mathrm{Y}_{9}$ bernilai negatif yang berarti JPRS mengalami penurunan laba bersih yang signifikan, hal ini sesuai dengan konsep yang dijelaskan oleh Kordlar \& Nikbakht (2011:340).

Krakatau Steel (KRAS) memiliki potensi kebangkrutan selama dua tahun berturut-turut yaitu tahun 2014 dan 2015 dikarenakan $\mathrm{Y}_{3}$ yang mengukur likuiditas bernilai negatif artinya KRAS memiliki kemampuan yang rendah dalam memenuhi kewajiban jangka pendeknya selan itu nilai $\mathrm{Y}_{5}$ dan $\mathrm{Y}_{6}$ memiliki nilai negatif yang memperbesar O-Score. Perusahaan Lion Metal Works (LION) tidak memiliki potensi kebangkrutan pada periode 2010 hingga 2015, Lionmesh Prima (LMSH) tidak memiliki potensi kebangkrutan pada tahun 2010 hingga tahun 2015, Pelat Timah Nusantara (NIKL) berpotensi mengalami kebangkrutan pada tahun 2011, 2013 2014 dan 2015 dikarenakan nilai $\mathrm{Y}_{5}, \mathrm{Y}_{6}$ dan $\mathrm{Y}_{9}$ bernilai negatif yang membuat $O$-Score semakin besar, sedangkan perusahaan Pelangi Indah Canindo (PICO) tidak memliki potensi kebangkrutan pada tahun 2010 hinga tahun 2015.

\section{Tabel 2. Hasil Analisis Kebangkrutan}

Hasil analisis prediksi kebangkrutan pada Tabel 2 menunjukkan dari 12 perusahaan sub sektor logam dan sejenisnya terdapat 6 perusahaan yang mengalami financial distress, perusahaan tersebut yaitu ALKA, ALMI, INAI, JPRS, KRAS, dan NIKL. ALKA pada periode 2010-2015 mengalami financial distress pada tahun 2013 dan 2015, hal ini mengartikan bahwa perusahaan pada tahun 2014 berhasil memperbaiki kinerja keuangan tahun sebelumnya, akan tetapi pada tahun 2015 mengalami financial distress kembali. ALMI pada periode 2010-2015 mengalami financial distress pada tahun 2011, 2013 dan 2014, artinya perusahaan ini berhasil memperbaiki kinerja keuangan pada tahun 2012 dan 2015. INAI pada periode 2010-2015 mengalami financial distress pada tahun 2013 saja, artinya perusahaan berhasil memperbaiki kinerja keuangan pada tahun 2014 dan 2015.

JPRS pada periode 2010-2015 mengalami financial distress pada tahun 2014 saja, artinya tahun 2015 perusahaan berhasil memperbaiki kinerja keuangannya. KRAS pada tahun 20102015 mengalami financial distress pada tahun 2014 dan 2015, artinya perusahaan pada tahun 2015 belum mampu memperbaiki kinerja 
keuangannya. NIKL pada periode 2010-2015 mengalami financial distress pada tahun 2011, 2013, 2014 dan 2015, artinya perusahaan pada tahun 2012 berhasil memperbaiki kinerja keuangannya, akan tetapi perusahaan tidak mampu mempertahankan perbaikan tersebut sehingga pada tahun 2013, 2014 dan 2015 perusahaan mengalami financial distress selama 3 tahun berturut-turut.

\section{KESIMPULAN \& REKOMENDASI}

Berdasarkan hasil penelitian yang telah dilakukan menggunakan analisis deskriptif gambaran analisis prediksi kebangkrutan model Ohlson pada perusahaan sub sektor logam dan sejeninya yaitu Alaska Industrindo (ALKA) selama periode 2010 hingga 2015 memiliki potensi kebangkrutan pada tahun 2013 saja, perusahaan Alumindo Light Metal Industry (ALMI) memiliki potensi kebangkrutan pada tahun 2011, 2013 dan 2014, Beton Jaya Manunggal (BTON) selama periode 2010 hingga 2015 tidak memiliki potensi kebangkrutan. Perusahaan Citra Turbindo (CTBN) pada periode 2010 hingga 2015 tidak memiliki potensi kebangkrutan, Gunawan Dianjaya Steel (GDST) tidak memiliki potensi kebangkrutan selama periode penelitian. Indal Alumunium Industry (INAI) berpotensi bangkrut pada tahun 2013, perusahaan Jaya Pari Steel (JPRS) memiliki potensi kebangkrutan hanya pada tahun 2014.

Krakatau Steel (KRAS) memiliki potensi kebangkrutan selama dua tahun berturut-turut yaitu tahun 2014 dan 2015. Perusahaan Lion Metal Works (LION) tidak memliki potensi kebangkrutan pada periode 2010 hingga 2015, Lionmesh Prima (LMSH) tidak memiliki potensi kebangkrutan pada tahun 2010 hingga tahun 2015, Pelat Timah Nusantara (NIKL) berpotensi mengalami kebangkrutan pada tahun 2011, 2013 2014 dan 2015 sedangkan perusahaan Pelangi Indah Canindo (PICO) tidak memliki potensi kebangkrutan pada tahun 2010 hinga tahun 2015.

Disarankan bagi perusahaan yang memiliki potensi kebangkrutan untuk memperbesar modal kerja atas total asset agar perusahaan mempunyai likuiditas baik, selain itu perusahaan disarankan meningkatkan laba bersih untuk memperbaiki profitabilitas perusahaan. Walaupun o-score perusahaan Citra Turbindo (CTBN), Gunawan Dianjaya Steel (GDST), dan Lion Metal Works (LION) menunjukkan perusahaan pada zona tidak bangkrut, akan tetapi o-score menunjukkan penurunan kinerja perusahaan. Disarankan perusahaan meningkatkan laba bersih agar terhindar dari financial distress dan kebangkrutan.

Penelitian ini diharapkan dapat membantu peneliti selanjutnya yang melakukan penelitian mengenai prediksi kebangkrutan, khususnya menggunakan model Ohlson. Peneliti selanjutnya dapat menggunakan objek perusahaan lainnya dengan tambahan-tambahan teori yang digunakan.

\section{DAFTAR PUSTAKA}

Altman, E.I. Hotchkiss, E. (2006). Corporate Financial Distress and Bankruptcy: Predict and Avoid Bankruptcy. Analyze and Invest in Distress Debt, (Vol.3), John Wiley \& Sons, Inc., USA.

Avenhuis, J. O. (2013). Testing the generalizability of the bankruptcy prediction models of Altman, Ohlson and Zmijewski for Dutch listed and large nonlisted firms. Retrieved from http://essay.utwente.nl/64326/

Berdine, H., kane, J., Ross, S., Spina, D. and Johnson, D. (1995). Performance appraisal design, development and implementation. in G. ferris, S. Rosen and D.Barnum (eds). Handbook f Human Resource Management. Cambridge, MA:Blackwell. pp. 462-93.

Brealey, R. A., Myers, S. C., \& Marcus, A. J. (2001). Fundamentals of Corporate Finance Third Edition. Mc Graw Hill.

Brigham, E. F., \& Daves, P. R. (2007). Intermediate financial management. The British Accounting Review. http://doi.org/10.1016/08908389(89)90100-5

Fahmi, Irham. 2014. Analisis Laporan Keuangan. Bandung: Alfabeta.

Gitman, L. J., \& Zutter, C. J. (2012). Principles of Managerial Finance. Financial Planning (13th ed.). Addison Wesley. http://doi.org/10.4324/9780080938196

Gitman, L. J., Zutter, C. J., Elali, W. ., \& AlRoubaie, A. . (2013). Lawrence J. Gitman, Chad J. Zutter, Wajeeh Elali, Amer AlRoubaie. (2013). Principles of Managerial Finance Arab World Edition . China: Pearson Education, Inc (Arab World). Pearson Education, Inc.

Harahap, S. S. (2009). Harahap, Sofyan Syafri. (2009). Analisis kritis atas laporan keuangan. Jakarta: Raja Grafindo Persada.

Hermawan, A. (2009). Penelitian Bisnis. Jakarta: PT. Grasindo.

Kleinert, M. K. (2014). Comparison of accounting-based bankruptcy prediction models of Altman ( 1968 ), Ohlson ( 1980 ), and Zmijewski ( 1984 ) to German and Belgian listed companies during 2008 2013, (July), 1-61.

Kordlar, A., \& Nikbakht, N. (2011). Comparing bankruptcy prediction models in Iran. 
Business Intelligence Journal, 4(2), 335$342 . \quad$ Retrieved from http://www.saycocorporativo.com/saycouk/ bij/journal/vol4no2/bij-vol4no2july2011.pdf\#page $=138$

Ohlson, J. a. (1980). Financial Ratios and the Probabilistic Prediction of Bankruptcy. Journal of Accounting Research, 18 (1), 109. http://doi.org/10.2307/2490395

Pena, T., Martinez, S., \& Abudu, B. (2009). Bankruptcy Prediction: A Comparison of Some Statistical and Machine Learning Techniques. Banco de Mexico Working Papers,

(18). http://doi.org/10.2139/ssrn.1525947

Sawir, Agnes. (2005). Analisis Kinerja Keuangan dan Perencanaan Keuangan
Perusahaan. Jakarta : PT Gramedia Pustaka

Suharsimi, A. (2009). Dasar-dasar Evaluasi Pendidikan. Jakarta: PT. Bumi AKsara.

$\mathrm{Xu}$, M., \& Zhang, C. (2009). Bankruptcy prediction: The case of Japanese listed companies. Review of Accounting Studies, $14 \quad$ (4), 534-558. http://doi.org/10.1007/s11142-008-9080-5

Undang-undang Republik Indonesia Kepailitan Nomor 4 Tahun 1998 Pasal 1 butir (1) tentang Kepailitan

Bisnis.com (2016). Harga Bijih Besi Kian Tertekan Akibat Melimpahnya Pasokan [Online]. Diakses dari http://market.bisnis.com/read/20160317/ 94/528727/harga-bijih-besi-kiantertekan-akibat-melimpahnya-pasokan 